\title{
BMJ Open Postoperative mortality in New Zealand following general anaesthetic: demographic patterns and temporal trends
}

\author{
Jason K Gurney (D) , ${ }^{1}$ Melissa McLeod (D) , James Stanley (D) , ${ }^{1}$ Doug Campbell, ${ }^{2}$ \\ Luke Boyle, ${ }^{3}$ Elizabeth Dennett, ${ }^{4,5}$ Sarah Jackson, ${ }^{6}$ Jonathan Koea, ${ }^{7}$ Dick Ongley, ${ }^{8}$ \\ Diana Sarfati ${ }^{1}$
}

To cite: Gurney JK, McLeod M, Stanley J, et al. Postoperative mortality in New Zealand following general anaesthetic: demographic patterns and temporal trends. BMJ Open 2020;10:e036451. doi:10.1136/ bmjopen-2019-036451

- Prepublication history for this paper is available online. To view these files, please visit the journal online (http://dx.doi org/10.1136/bmjopen-2019036451).

Received 16 December 2019 Revised 19 July 2020 Accepted 05 August 2020
Check for updates

(C) Author(s) (or their employer(s)) 2020. Re-use permitted under CC BY-NC. No commercial re-use. See rights and permissions. Published by BMJ.

For numbered affiliations see end of article.

Correspondence to Dr Jason K Gurney; jason.gurney@otago.ac.nz

\section{ABSTRACT}

Objectives In this manuscript, we describe broad trends in postoperative mortality in New Zealand (a country with universal healthcare) for acute and elective/waiting list procedures conducted between 2005 and 2017.

Design, participants and setting We use high-quality national-level hospitalisation data to compare the risk of postoperative mortality between demographic subgroups after adjusting for key patient-level confounders and mediators. We also present temporal trends and consider how rates in postoperative death following acute and elective/waiting list procedures have changed over this time period.

Results and conclusion A total of 1836683 unique patients accounted for 3117374 admissions in which a procedure was performed under general anaesthetic over the study period. We observed an overall 30 -day mortality rate of 0.5 per 100 procedures and a 90 -day mortality rate of 0.9 per 100 . For acute procedures, we observed a 30 -day mortality rate of 1.6 per 100 , compared with 0.2 per 100 for elective/waiting list procedures. In terms of procedure specialty, respiratory and cardiovascular procedures had the highest rate of 30-day mortality (age-standardised rate, acute procedures: 3-6 per 100; elective/waiting list: 0.7-1 per 100). As in other contexts, we observed that the likelihood of postoperative death was not proportionally distributed within our population: older patients, Māori patients, those living in areas with higher deprivation and those with comorbidity were at increased risk of postoperative death, even after adjusting for all available factors that might explain differences between these groups. Increasing procedure risk (measured using the Johns Hopkins Surgical Risk Classification System) was also associated with an increased risk of postoperative death. Encouragingly, it appears that risk of postoperative mortality has declined over the past decade, possibly reflecting improvements in perioperative quality of care; however, this decline did not occur equally across procedure specialties.

\section{INTRODUCTION}

More than four million people die within 30 days of surgery every year. ${ }^{1}$ Of the 1.2 million admissions in New Zealand between 2009
Strengths and limitations of this study

- A key strength of this study is the national and temporal coverage of the surgical cohort and outcome data.

- Another key strength is the national data linkage available in New Zealand, which enabled us to follow patients beyond their discharge from hospital in order to measure 30-day and 90-day mortality outcomes.

- We have intentionally focused exclusively on procedures performed under general anaesthesia, and therefore do not include procedures performed under neuraxial block and/or regional anaesthesia.

- Due to data availability, it was not possible in our study to adequately investigate the role of hospital volume or clustering of patients at a hospital level.

and 2013 for procedures performed under general anaesthesia, $0.6 \%$ were followed by a death within 30 days, with the majority $(72 \%)$ occurring following an acute admission. ${ }^{2}$

In a clinical setting, the key means of preventing postoperative complications (and death) include: (a) patient selection, using tools such as risk calculators ${ }^{3}$, (b) optimisation of the condition of the patient (which may include 'prehabilitation'), (c) altering operation and treatment modalities to suit the needs and condition of the patient, (d) preoperative prevention measures including adherence to robust and standardised clinical checklists and (e) good postoperative management, including management of comorbidities $^{4}$ and selection of the postoperative location (eg, ward, intensive care, outside hospital). Adherence to these factors will vary between clinical contexts and should change over time as new and improved standards are developed and implemented. 
The risk of postoperative mortality is not proportionally shared across the population. In terms of patientlevel factors, advancing age ${ }^{5-7}$ minority or indigenous ethnicity $^{8-16}$ and socioeconomic deprivation ${ }^{2}{ }^{17-19}$ are known to confer increased risk of postoperative death. Patient comorbidity is also a strong risk factor, with risk of postoperative death increasing with comorbidity severity. ${ }^{20-22}$ These (and other) risk factors do not act in isolation from each other: rather, they combine with the type and complexity of the procedure being undertaken (ie, severity or risk) and the urgency of the procedure (ie, acuity) to attenuate or amplify an individual's risk of death following surgery.

In this manuscript, we describe trends in postoperative mortality in New Zealand (a country with universal healthcare) for acute and elective/waiting list procedures conducted between 2005 and 2017. We compare the risk of postoperative mortality between demographic subgroups after adjusting for key patient-level confounders and mediators. We also present temporal trends and consider how rates in postoperative death following acute and elective/waiting list procedures have changed over this time period.

\section{METHODS}

\section{Participants and data sources}

Our study cohort included all individuals who underwent a procedure under general anaesthesia (International Classification of Diseases [ICD-10-AM] third edition codes: 9251410-9251499) between 1 January 2005 and 31 December 2017. National-level hospitalisation data (National Minimum Dataset, NMDS ${ }^{23}$ from all publicly funded procedures were included as well as privately funded procedures conducted in those private hospitals that report to the national collections. New Zealand has 84 public hospitals and 73 private hospitals, ${ }^{24}$ with the completeness of reporting of privately funded procedures varying annually. ${ }^{25}$ These data were used to find eligible hospital admissions over the study period that included procedures performed under general anaesthetic. To allow for patients who had more than one operation performed under general anaesthetic during their admission, admissions were further divided into the individual days that procedures were performed during the admission, and this was used as the unit of analysis for this study.

Using the residency flag on the NMDS, we restricted our analysis to New Zealand residents to ensure follow-up for postoperative death, which resulted in the exclusion of 103617 procedures (3.1\% of all procedures). We excluded patients who had an American Society of Anaesthesiologists (ASA) score of 6 (indicating that the procedure was being undertaken on patients with irreversible cessation of brain function for the purposes of organ donation) or were coded as having a removal of a donor heart or lung, which resulted in the exclusion of 250 procedures $(<0.01 \%$ of all procedures $)$.
Patient comorbidity at the start of each admission (see the Variables below) was measured using data on recorded diagnoses from public and private hospital admission records for the 5-year period prior to the admission using an encrypted patient identifier (National Health Index number, NHI). Date of death was defined using the date of death variable that appears on the NHI dataset, which is derived from the births, deaths and marriages office. ${ }^{26}$

\section{Variables}

All variables were derived from the NMDS dataset. Procedure specialty was determined by mapping each procedure code to the Australasian College of Health Informatics procedure code 'block', which is comprised of blocks of procedures organised according to anatomical specialty. ${ }^{27}$ Procedure risk was established using a modified version $^{3}$ of the Johns Hopkins Surgical Risk Classification System, ${ }^{28}$ which classifies surgical risk into five categories according to factors such as the invasive nature of the procedure and the potential for blood loss. Procedure codes were mapped to the risk classification system as part of a previous study. ${ }^{3}$

Patient age was defined at the time of procedure (categorised as $<25,25-49,50-64,65-74$ or $75+$ ). These age categories are wider among younger (lower risk) age groups and narrower among older (higher risk) age groups, in an attempt to reflect the strong increase in risk of postoperative death with increasing age. Patient sex was defined at the time of the procedure and categorised as either male or female, with sex data missing for 18 admissions and procedure-days $(<0.001 \%$ of admissions and total procedures). Ethnicity was defined using prioritised ethnicity at the time of the admission from NMDS data and categorised as either Māori, Pacific, Asian, European or Middle Eastern/Latin American/African/Other (hereafter referred to as MELAA/Other) ${ }^{29}$ Ethnicity data were sourced from NMDS, which is guided by ethnicity data protocols, where ethnicity is ideally self-identified by the patient.

Patient deprivation at the time of procedure was determined using New Zealand's 2013 Deprivation Index (NZDep), which uses an individuals' residential address to define area deprivation. ${ }^{30}$ NZDep deciles were collapsed into quintiles from 1 (least deprived) to 5 (most deprived). To determine NZDep, the domicile in which an individual lived at the time of the procedure was mapped to its respective 2013 Census Area Unit (CAU). In cases where domicile codes could not be mapped to the 2013 CAU due to changes in CAU definition between the 2006 and 2013 Census ( $\mathrm{n}=163079$ or $5.2 \%$ of admissions), NZDep score and Urban/Rural Profile Classification (URPC) were determined using the 2006 mapping. Missing data prevented attribution of NZDep for 51151 admissions or 53559 procedures (1.7\% of the total procedures). Patient rurality was defined using a modified version of the URPC, ${ }^{31}$ with the area where patient lived at the time of the procedure classified as urban (main urban area + satellite urban area), independent urban or 
rural. Missing data prevented attribution of rurality for 53486 admissions or 55999 procedures (1.7\% of the total procedures). There is an overlap between missingness of deprivation and rurality data, driven by missing CAU data.

Patient comorbidity was defined using the M3 Index. ${ }^{32}$ For each patient, NMDS data from the 5-year period prior to the date of admission for the given procedure were searched for the presence of any of the 61 conditions included in the M3 Index using ICD-10 codes. Each condition was coded as either present or not present ( 1 if present, 0 if not present), and each condition was then weighted according to its relationship with mortality in the general population (see Stanley and Sarfati $^{32}$ for weights and more information about the M3 Index). Condition weights were then summed for each patient at their admission to give their M3 Index score. For descriptive analysis, M3 scores were categorised as $0,>0-1,>1-2,>2-3$ or $3+$, with higher score indicating greater comorbidity. For regression models, M3 score was included as a splined variable ${ }^{32}$ with knots placed at the 0th, 90th and 95th percentiles. ${ }^{33}$ ASA physical status score was determined from ICD anaesthesia codes and categorised as either $1-2,3,4-5$ or unknown. ${ }^{16}$ In those instances where more than one ASA score was coded on a given procedure-day, a give-way rule was applied wherein the worst, ASA score was retained for that procedure-day.

All procedures were assigned an admission type depending on the reason for their hospital admission, with admission type categorised as either acute or elective/waiting list. Postoperative mortality was defined as death from any cause recorded within either 30 or 90 days of that procedure, inclusive of the date of procedure.

\section{Statistical analysis}

Descriptive analyses included crude counts and rates (per 100 procedures) of 30-day and 90-day mortality. When investigating rates of 30-day mortality (including temporal trends), we age-standardised rate data to the age structure of those who underwent a procedure in 2010 (separately for both acute and elective/waiting list procedures), in order to account for changes in population age structure over time. To test for notable increases or decreases in the rate of postoperative death over time, we calculated a two-sided Cochran-Armitage test for trend. ${ }^{34}$ As part of the temporal trend analysis, we also explored the absolute rate of both acute and elective/waiting list procedures performed on New Zealanders, using the Statistics New Zealand estimated residential population for each of the years in the study period (2005-2017) as the denominator (online supplemental material 1). ${ }^{35}$

In order to establish the relationship between our measured covariates and risk of 30-day mortality, we conducted Cox proportional hazards regression modelling. Within the Cox model, we censored procedures when either (a) no death occurred within 30 days of the procedure or (b) if a subsequent procedure occurred within a 30-day period from the date of the original procedure. ${ }^{36}$ As such, for those who had multiple procedures within a given 30-day period, the last procedure (rather than the first) was used as the index procedure (see online supplemental material 2 and online supplemental material 2 table for further detail). A total of 2960 individuals who died within 30 days of a procedure had had at least one other previous procedure within the 30-day period prior to death ( $18 \%$ of all deaths within 30 days). HRs and their 95\% CIs were determined for the risk of 30-day mortality for each modelled variable (procedure type, procedure risk, age, sex, ethnicity, deprivation, rurality, M3 score, ASA score), giving the risk for each variable adjusted for all other covariates in the model.

Data management and analysis were performed in SAS V.9.4 (SAS Institute) and Microsoft Excel V.2016 (Microsoft Corporation, USA). The data used for the analysis in this study are available on request from the New Zealand Ministry of Health for eligible research groups (Ministry of Health data extract number 2018-0452).

\section{Patient and public involvement}

The development of our study objectives was informed by the need to monitor population-level rates of postoperative mortality and in particular assess how these rates differ within the population. However, patients were not directly involved in the study.

\section{RESULTS}

A total of 1836683 unique patients accounted for 3117374 admissions in which a procedure was performed under general anaesthetic over the study period. Since only $2 \%$ of admissions had more than one procedure-day where a general anaesthetic was administered, we finished with a total of 3217823 unique procedure-days. Rates of 30-day and 90-day mortality following a procedure under general anaesthetic are shown in table 1 and online supplemental material 3 respectively, stratified by covariates. Results from the multivariate Cox regression models are shown in table 2.

In total, of the 3271823 procedures performed under general anaesthetic over the study period, a total of 16630 patients died within 30 days (crude rate: 0.5 per 100 procedures) and 28488 died within 90 days (0.9 per 100). Of the 780009 acute procedures performed over the study period, a total of 12220 patients died within 30 days of their procedure (crude rate: 1.6 per 100). When stratified by procedure specialty, the highest rate of 30-day mortality following acute procedures was observed for respiratory system procedures (age-standardised rate: 6.3 per 100$)$, followed by neurosurgery (3.6 per 100$)$, cardiovascular (3.3 per 100), digestive system (2.1 per $100)$, urinary system (1.4 per 100), musculoskeletal (1.0 per 100) and other procedures (0.6 per 100).

Of the 2437814 elective/waiting list procedures, a total of 4410 patients died within 30 days (0.2 per 100 procedures). The highest rate of 30-day mortality following elective/waiting list procedures was again observed for respiratory system procedures (age-standardised rate: 
Table 1 Postoperative mortality within 30 days of an acute and elective/waiting list procedure performed under general anaesthetic, for the total population and by demographic subgroup

\begin{tabular}{|c|c|c|c|c|c|c|c|c|}
\hline & \multicolumn{4}{|c|}{ Acute } & \multicolumn{4}{|c|}{ Elective/waiting list } \\
\hline & \multirow{2}{*}{$\begin{array}{l}\text { Procedures } \\
\mathbf{n}\end{array}$} & \multirow{2}{*}{$\begin{array}{l}\text { Deaths } \\
\mathbf{n} \\
\end{array}$} & \multicolumn{2}{|c|}{ Death rate $(n / 100)$} & \multirow{2}{*}{$\begin{array}{l}\text { Procedures } \\
\mathbf{n}\end{array}$} & \multirow{2}{*}{$\begin{array}{l}\text { Deaths } \\
\text { n }\end{array}$} & \multicolumn{2}{|c|}{ Death rate $(n / 100)$} \\
\hline & & & Crude & $\begin{array}{l}\text { Age standardised } \\
(95 \% \mathrm{Cl})\end{array}$ & & & Crude & $\begin{array}{l}\text { Age } \\
\text { standardised } \\
(95 \% \mathrm{Cl})\end{array}$ \\
\hline Total procedures & 780009 & 12220 & 1.6 & - & 2437814 & 4410 & 0.2 & - \\
\hline \multicolumn{9}{|l|}{ Procedure specialty } \\
\hline Digestive system & 185469 & 4185 & 2.3 & 2.1 (2 to 2.2 ) & 381443 & 1523 & 0.4 & $0.3(0.3$ to 0.3$)$ \\
\hline Respiratory system & 12089 & 723 & 6 & $6.3(6.1$ to 6.5$)$ & 30557 & 377 & 1.2 & 1 (1 to 1.1$)$ \\
\hline Neurosurgery & 28243 & 1101 & 3.9 & 3.6 (3.5 to 3.8 ) & 66445 & 255 & 0.4 & $0.4(0.4$ to 0.4$)$ \\
\hline Musculoskeletal & 268160 & 3449 & 1.3 & 1 (0.9 to 1.1$)$ & 585997 & 504 & 0.1 & $0.1(0.1$ to 0.1$)$ \\
\hline Urinary system & 19105 & 369 & 1.9 & 1.4 (1.3 to 1.5$)$ & 102059 & 264 & 0.3 & 0.2 (0.1 to 0.2$)$ \\
\hline 2 & 310735 & 2032 & 0.7 & 0.9 (0.8 to 1$)$ & 1252395 & 1001 & 0.1 & $0.1(0.1$ to 0.1$)$ \\
\hline 3 & 238087 & 3817 & 1.6 & $1.2(1.1$ to 1.3$)$ & 503548 & 668 & 0.1 & $0.1(0.1$ to 0.1$)$ \\
\hline 4 & 63632 & 3943 & 6.2 & 4 (3.8 to 4.1$)$ & 164375 & 1586 & 1 & 0.6 (0.6 to 0.7$)$ \\
\hline 5 (highest risk) & 27235 & 1652 & 6.1 & 5.1 (4.9 to 5.3 ) & 52954 & 892 & 1.7 & 1.2 (1.2 to 1.3$)$ \\
\hline \multicolumn{9}{|l|}{ Age (years) } \\
\hline$<25$ & 260373 & 609 & 0.2 & - & 687778 & 210 & 0 & - \\
\hline $25-49$ & 243794 & 1015 & 0.4 & - & 715463 & 322 & 0 & - \\
\hline $50-64$ & 120772 & 1927 & 1.6 & - & 541829 & 844 & 0.2 & - \\
\hline $65-74$ & 69109 & 2462 & 3.6 & - & 300342 & 1150 & 0.4 & - \\
\hline Pacific & 64403 & 569 & 0.9 & 1.6 (1.5 to 1.7$)$ & 113784 & 168 & 0.1 & 0.3 (0.3 to 0.3$)$ \\
\hline Asian & 36299 & 429 & 1.2 & 1.7 (1.6 to 1.8$)$ & 117084 & 107 & 0.1 & 0.2 (0.1 to 0.2$)$ \\
\hline European & 507878 & 9411 & 1.9 & 1.4 (1.3 to 1.5$)$ & 1777708 & 3417 & 0.2 & 0.2 (0.1 to 0.2$)$ \\
\hline MELAA/Other & 22965 & 312 & 1.4 & 1.4 (1.3 to 1.5$)$ & 123359 & 133 & 0.1 & 0.1 (0.1 to 0.1$)$ \\
\hline \multicolumn{9}{|l|}{$\begin{array}{l}\text { Deprivation (NZDep } \\
\text { Decile) }\end{array}$} \\
\hline $1-2$ & 112029 & 1544 & 1.4 & 1.3 (1.2 to 1.4$)$ & 450239 & 527 & 0.1 & 0.1 (0.1 to 0.1$)$ \\
\hline $3-4$ & 118095 & 1716 & 1.5 & $1.3(1.2$ to 1.4$)$ & 427068 & 610 & 0.1 & 0.1 (0.1 to 0.2$)$ \\
\hline $5-6$ & 140104 & 2384 & 1.7 & 1.5 (1.4 to 1.6$)$ & 475398 & 874 & 0.2 & 0.2 (0.1 to 0.2$)$ \\
\hline $7-8$ & 171830 & 3063 & 1.8 & 1.6 (1.5 to 1.7$)$ & 526368 & 1136 & 0.2 & 0.2 (0.2 to 0.2$)$ \\
\hline $9-10$ & 222015 & 3291 & 1.5 & 1.8 (1.7 to 1.9$)$ & 521118 & 1195 & 0.2 & 0.3 (0.2 to 0.3$)$ \\
\hline \multicolumn{9}{|l|}{ Rurality } \\
\hline Urban & 580028 & 9011 & 1.6 & 1.5 (1.4 to 1.6$)$ & 1758564 & 3006 & 0.2 & 0.2 (0.2 to 0.2$)$ \\
\hline Independent urban & 90224 & 1867 & 2.1 & 1.7 (1.6 to 1.9$)$ & 317170 & 852 & 0.3 & 0.2 (0.2 to 0.2$)$ \\
\hline Rural & 93287 & 1117 & 1.2 & 1.3 (1.2 to 1.4$)$ & 322551 & 480 & 0.1 & 0.2 (0.1 to 0.2$)$ \\
\hline \multicolumn{9}{|l|}{$\begin{array}{l}\text { Comorbidity (M3 Index } \\
\text { category) }\end{array}$} \\
\hline 0 & 494470 & 1618 & 0.3 & 0.6 (0.6 to 0.7$)$ & 1753031 & 428 & 0 & 0 (0 to 0$)$ \\
\hline
\end{tabular}

Continued 


\begin{tabular}{|c|c|c|c|c|c|c|c|c|}
\hline & \multicolumn{4}{|c|}{ Acute } & \multicolumn{4}{|c|}{ Elective/waiting list } \\
\hline & \multirow{2}{*}{$\begin{array}{l}\text { Procedures } \\
\text { n }\end{array}$} & \multirow{2}{*}{$\begin{array}{l}\text { Deaths } \\
\text { n }\end{array}$} & \multicolumn{2}{|c|}{ Death rate $(n / 100)$} & \multirow{2}{*}{$\begin{array}{l}\text { Procedures } \\
\text { n }\end{array}$} & \multirow{2}{*}{$\begin{array}{l}\text { Deaths } \\
\text { n }\end{array}$} & \multicolumn{2}{|c|}{ Death rate $(n / 100)$} \\
\hline & & & Crude & $\begin{array}{l}\text { Age standardised } \\
(95 \% \mathrm{Cl})\end{array}$ & & & Crude & $\begin{array}{l}\text { Age } \\
\text { standardised } \\
(95 \% \mathrm{Cl})\end{array}$ \\
\hline$>0-1$ & 196780 & 4516 & 2.3 & $1.6(1.5$ to 1.7$)$ & 494940 & 1591 & 0.3 & 0.2 (0.2 to 0.2$)$ \\
\hline$>1-2$ & 57886 & 3293 & 5.7 & 3.2 (3.1 to 3.4$)$ & 123863 & 1201 & 1 & 0.7 (0.6 to 0.7$)$ \\
\hline$\geq 3$ & 6708 & 744 & 11.1 & 7 (6.7 to 7.2$)$ & 11938 & 288 & 2.4 & 1.7 (1.7 to 1.8$)$ \\
\hline \multicolumn{9}{|l|}{ ASA score } \\
\hline $1-2$ & 484622 & 716 & 0.1 & $0.3(0.2$ to 0.3$)$ & 1122776 & 481 & 0 & $0.1(0$ to 0.1$)$ \\
\hline 3 & 115815 & 3544 & 3.1 & 1.7 (1.6 to 1.9$)$ & 226284 & 1565 & 0.7 & $0.4(0.4$ to 0.5$)$ \\
\hline $4-5$ & 37847 & 5450 & 14.4 & $10.4(10.1$ to 10.7$)$ & 25978 & 1313 & 5.1 & 3.8 (3.7 to 3.8$)$ \\
\hline
\end{tabular}

MELAA, Middle Eastern/Latin American/African.

1.0 per 100$)$, followed by cardiovascular $(0.7$ per 100$)$, neurosurgery ( 0.4 per 100$)$, digestive system ( 0.3 per $100)$, urinary system (0.2 per 100), musculoskeletal (0.1 per 100) and other procedures (0.1 per 100). Over 90 days, the number of deaths following an acute procedure increased to 19326 (2.5 per 100) and the number of deaths following elective/waiting list procedure increased to 9162 (0.4 per 100). 90-day trends in terms of procedure specialty remained similar to those observed at 30 days.

Temporal trends in 30-day mortality are shown in figure 1 for all combined procedures, while figure 2 shows 30-day mortality stratified by procedure specialty and risk (statistical tests for trend ( $p$ values) are shown in online supplemental material 4). Total rates of 30-day mortality appeared to decline over the study period, for both acute ( $p$ for trend $=0.097$ ) and elective/waiting list ( $p$ for trend $<0.001$ ) procedures (figure 1), though the statistical evidence was less robust for acute procedures. When stratified by procedure specialty (figure 2 ), we observed some evidence of improvements over time in 30-day mortality for some specialties, particularly both acute and elective/ waiting list digestive system procedures (both $\mathrm{p}$ for trend $<0.01)$. However, trends were somewhat erratic for those specialties with low absolute numbers of deaths (such as respiratory and urinary procedures), and so results should be interpreted with caution for these procedures. Rates of 30-day mortality following cardiovascular procedures appeared relatively stable over time ( $p$ for trend: acute procedures 0.45 ; elective/waiting list procedures $0.91)$. When stratified by procedure risk, we observed an apparent improvement in postoperative mortality over time particularly for the higher risk procedures (eg, elective/waiting list procedures, procedure risk 5: $\mathrm{p}$ for trend $<0.01$ ).

The rate of postoperative mortality increased with age for both acute and elective/waiting list procedures: after adjusting for all other covariates within the Cox regression models (including sex, ethnicity, deprivation, rurality, comorbidity, ASA score, procedure specialty and procedure risk), there remained a clear relationship between increasing age and risk of death within 30 days of an acute or elective/waiting list procedure (eg, adjusted HR of 30-day mortality following an acute procedure, $<25$ years: reference group; 75+years: 6.98, 95\% CI 6.36 to 7.70). There was no evidence of strong disparities in postoperative mortality between men and women. Once adjusted for the included covariates, disparities in postoperative mortality for other ethnic groups compared with Europeans largely disappeared for acute procedures; however, Māori patients were $30 \%$ more likely to die within 30 days of an elective/waiting list procedure than European patients $(1.32,95 \%$ CI 1.20 to 1.50$)$, while Pacific (0.93, $95 \%$ CI 0.79 to 1.10$)$, Asian $(0.85,95 \%$ CI 0.70 to 1.00$)$ and MELAA/Other (1.06, 95\% CI 0.89 to 1.30$)$ patients appeared no more or less likely. Once adjusted for other covariates, there remained a pronounced risk gradient for elective/waiting list procedures with increasing deprivation (NZDep deciles 1-2 reference group; NZDep deciles 9-10 1.33, 95\% CI 1.19 to 1.50). Those living in rural areas appeared to have a similar rate of postoperative death within 30 or 90 days of a procedure compared with those living in urban areas.

Patients with a high comorbidity burden had a substantially higher rate of death within 30 or 90 days of an acute or elective/waiting list procedure; for example, those with an M3 Index score of 3 (indicating high comorbidity burden) were more than three times more likely to die within 30 days of an acute procedure than those with a comorbidity score of zero (adjusted HR 3.19, 3.01-3.40) and 10 times more likely to die within 30 days of an elective/waiting list procedure (10.08, 95\% CI 9.75 to 12.00$)$. Those with an ASA score of 4-5 were more than 20 times more likely to die within 30 days of an acute procedure than those with an ASA score of 1-2 (21.14, 95\% CI 19.39 to 23.00) and nearly 15 times more likely following an elective/waiting list procedure (14.73, 95\% CI 13.12 
Table 2 Comparison between subgroups of the adjusted likelihood of death within 30 days of an acute and elective/waiting list procedure

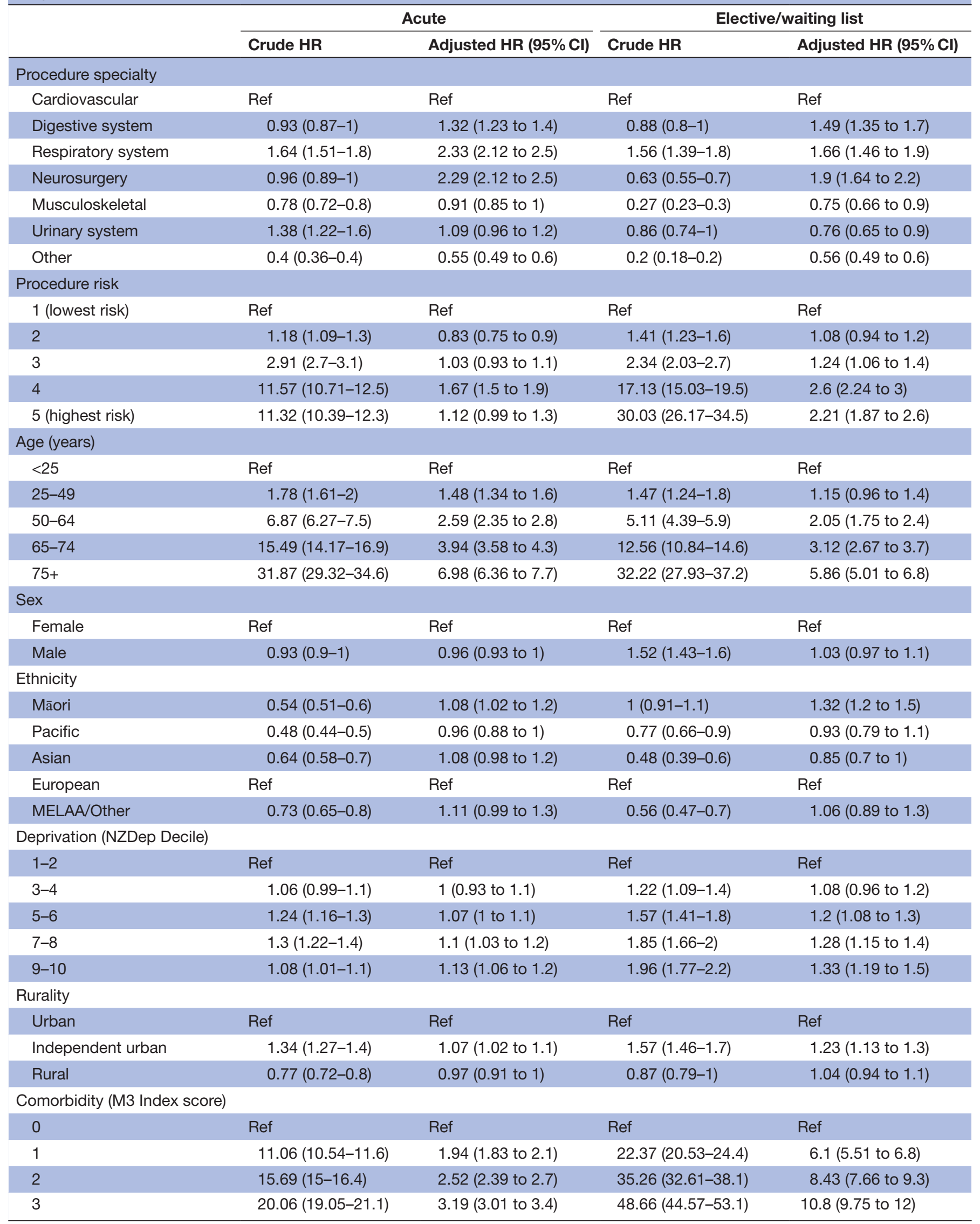




\begin{tabular}{|c|c|c|c|c|}
\hline & \multicolumn{2}{|c|}{ Acute } & \multicolumn{2}{|c|}{ Elective/waiting list } \\
\hline & Crude HR & Adjusted HR $(95 \% \mathrm{Cl})$ & Crude HR & Adjusted HR $(95 \% \mathrm{Cl})$ \\
\hline \multicolumn{5}{|l|}{ ASA score } \\
\hline 3 & 20.95 (19.33-22.7) & 5.48 (5.03 to 6$)$ & 16.19 (14.62-17.9) & 3.33 (2.99 to 3.7 ) \\
\hline $4-5$ & 105.67 (97.75-114.2) & 21.14 (19.39 to 23$)$ & $121.46(109.41-134.8)$ & $14.73(13.12$ to 16.5$)$ \\
\hline
\end{tabular}

$1=$ adjusted for all other covariates.

MELAA, Middle Eastern/Latin American/African.

to 16.50), even after adjusting for comorbidity (and all other covariates).

Risk of postoperative mortality increased with increasing prespecified procedure risk; once adjusted for covariates, the increase between adjacent procedure risk categories became less obvious for acute procedures, but remained for elective/waiting list procedures (eg, procedure risk category 1: reference group; procedure risk category 5: adjusted HR 2.21, 95\% CI 1.87 to 2.60). Compared with cardiovascular procedures, and once adjusted for covariates, respiratory procedures, digestive system procedures and neurosurgery had higher risk of death following either acute or elective/waiting list procedures (eg, acute procedures: adjusted HRs 1.3-2.3), while musculoskeletal

A)

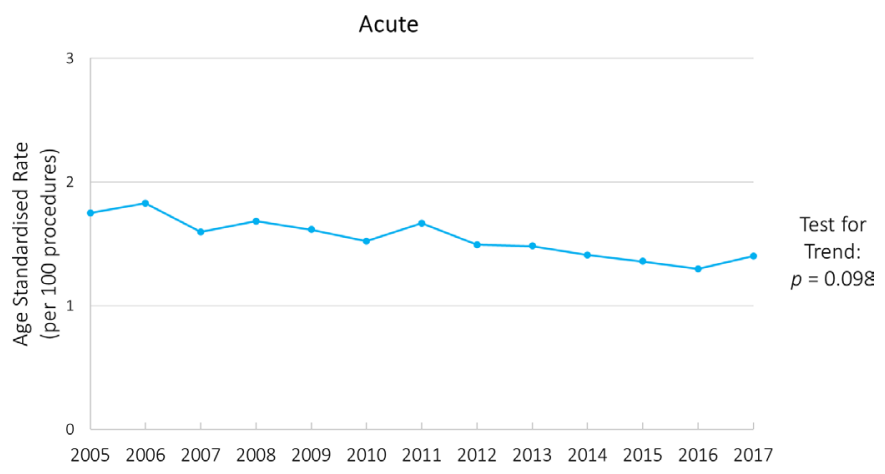

B)

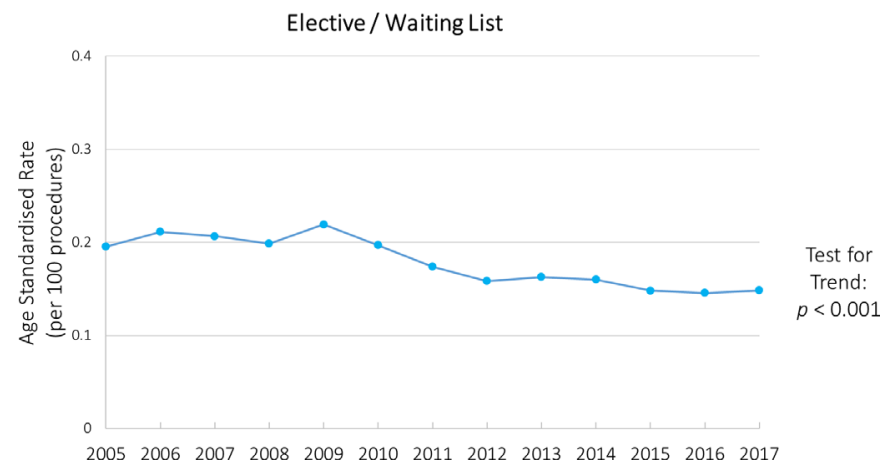

Figure 1 Age-standardised temporal trends in 30-day mortality among those undergoing $(A)$ acute or $(B)$ elective/ waiting list procedures under general anaesthetic. and urinary system procedures had a lower or similar risk of death (adjusted HRs 0.9-1.1). However, it should be noted that the selection of a reference group for this procedure-based analysis was arbitrary.

\section{DISCUSSION}

Using national-level data, we observed a 30-day mortality rate following any procedure under general anaesthetic of 0.5 per 100 procedures. A similar study in Scotland observed an in-hospital mortality rate of 0.46 per 100 procedures when examining all surgical procedures (regardless of anaesthetic type) conducted in 2014. ${ }^{37}$ We observed that postoperative death with 30 days of a procedure is much more likely following acute (1.6 per 100 procedures) than elective/waiting list procedures $(0.2$ per 100), which is a reflection of the emergency nature of the procedure among those admitted acutely, which will include instability of the condition of the patient. These rates are comparable to those observed in a recent study from the USA, ${ }^{38}$ and the acute versus elective/waiting list trend has been consistently observed worldwide, with a 28-country European study showing that in-hospital death is more than three times as likely following an acute procedure compared with an elective one. $^{39}$

In absolute terms, the procedure specialty with the highest number of postoperative death was digestive system procedures, followed by musculoskeletal and cardiovascular procedures (largely driven by volumes of patients undergoing these procedures). However, considered as risk per 100 operations, respiratory procedures had the highest rates of postoperative death following either acute ( 6 per 100) or elective/waiting list (1 per $100)$ procedures, although these rates varied erratically over time (see the Temporal trends below). These rates are somewhat similar to other reports: a Norwegian study on postoperative mortality following lung cancer resection observed a 30-day mortality rate of 4 per 100 procedures ${ }^{40}$ while an international study of select centres in 14 countries observed a 30-day mortality rate of 1.7 per 100 following any thoracic surgery. These earlier studies were not stratified by admission type. 

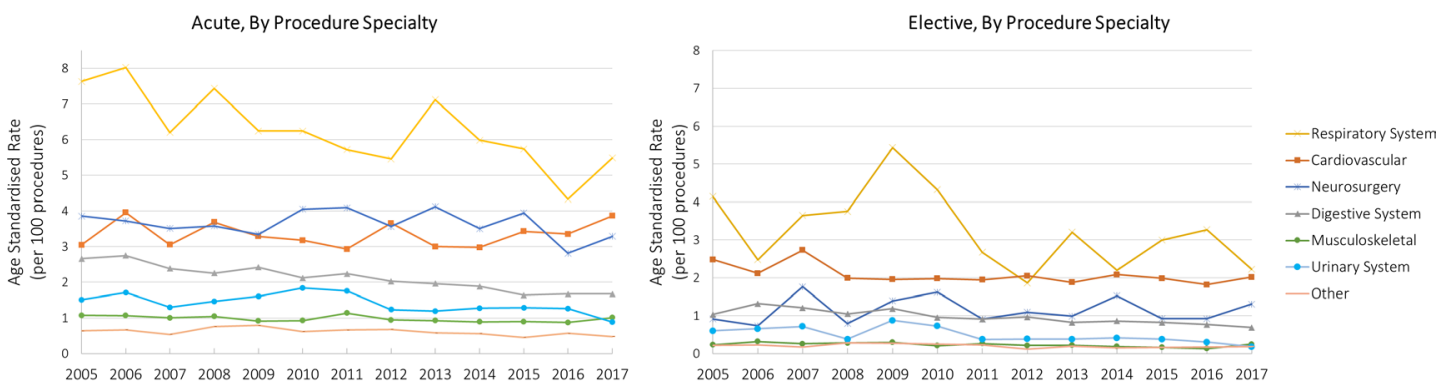

B)
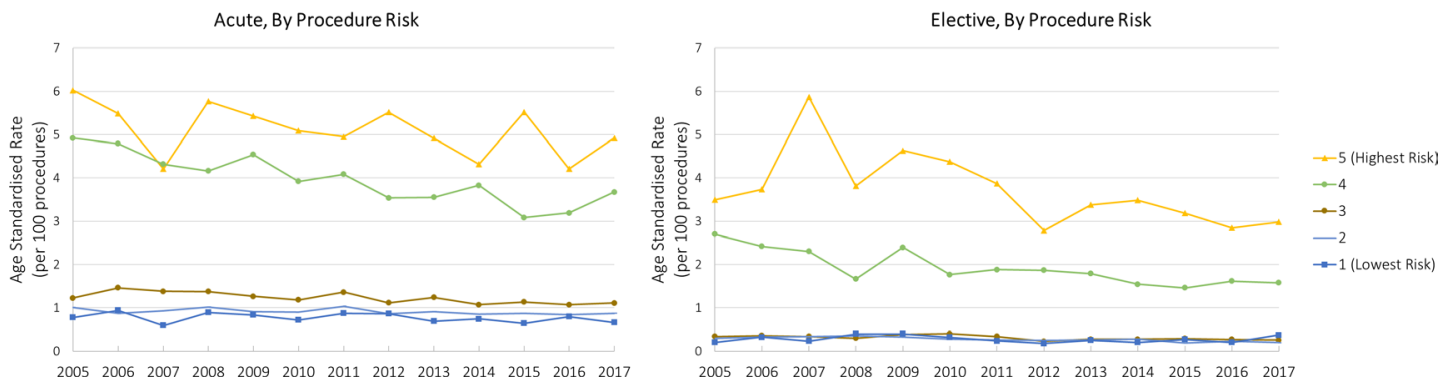

Figure 2 Age-standardised temporal trends 30-day mortality among those undergoing acute or elective/waiting list procedures under general anaesthetic, by (A) procedure specialty and (B) procedure risk. Rate data, confidence limits and tests for trend ( $\mathrm{p}$ values) are shown in online supplemental material 4.

\section{Temporal trends}

We observed that the rate of postoperative mortality appears to have reduced over time for both acute and elective/waiting list procedures (figure 1, standardised by age). When stratified by procedure specialty (figure 2), we observed substantial reductions in postoperative death for several specialties (particularly digestive system procedures), but no apparent change for others including cardiovascular procedures. This general reduction in postoperative mortality is consistent with that observed in England between 1998 and 2013, as is the observation that rates of postoperative death following cardiovascular (particularly cardiac) procedures have remained stable over time. ${ }^{41}$ Other studies examining specific procedures have noted improvements over time for several procedure types ${ }^{4-44}$ including digestive system procedures. ${ }^{43}$

The drivers behind these improvements are likely to be multifactorial, but in the New Zealand context, they may include improvements in surgical standard setting by central government and relevant clinical governance bodies (eg, the Royal Australasian College of Surgeons). Specifically, it is possible that temporal improvements may reflect heightened preoperative multidisciplinary input, particularly in high risk patients, improved preoperative health optimisation (including prehabilitation) and improved identification of high risk patients with preassessment clinics. In Scotland, a $37 \%$ reduction in in-hospital death following surgery was observed after the introduction of the WHO Surgical Safety Checklist as part of the Scottish Patient Safety Programme. ${ }^{37}$ Nepogodiev and colleagues noted a similar improvement following the introduction of the checklist in England. ${ }^{41}$ In
New Zealand, intraoperative factors that may have improved over the study period include initiatives like surgical checklists and the availability of Networkz (a national in situ training programme for surgical teams). Improvements in postoperative factors include increased standardisation of postoperative care through programmes like the enhanced recovery after surgery and End PJ Paralysis programmes. ${ }^{45}$

However, the observed decline may not be entirely due to changes in the quality of perioperative care: other contributing factors could include increased volumes of procedures on lower risk populations and/or a restriction on access to surgery among higher risk populations. Further work is required to unpick the true drivers of this apparent gradual decline.

\section{Risk factors}

After adjusting for all other covariates, including procedure specialty, we observed that risk of postoperative death was strongly related to increasing age, indigenous Māori ethnicity, high levels of deprivation and increasing comorbidity and ASA levels, and the risk of the procedure itself. Pooling data from 500 hospitals across 28 European countries, Pearse $e t a l^{39}$ similarly observed that risk of in-hospital death following surgery was strongly related to increasing age, increasing ASA score, increasing grade of surgery (broadly comparable to procedure risk) and the presence of substantial comorbidities. The lack of a rural effect-where those in rural areas appear no more likely to die than those in urban areas-has been observed before in other procedure-specific studies in New Zealand. ${ }^{46}$ 
In keeping with previous observations, ${ }^{1647}$ we found that Māori patients tend to be more likely to die within 30 days of a procedure than other ethnic groups, including Pacific patients. We previously observed that Māori patients (but not Pacific patients) with diabetes were nearly $50 \%$ more likely to die within 30 days of a major lower limb amputation than European patients with diabetes-even after adjusting for differences in age, sex, deprivation, rurality, hospital volume, admission type and comorbidity. ${ }^{5}$ This suggests that the higher risk of postoperative morality for Maori patients is in part due to institutionalised racism in the healthcare system, ${ }^{48}{ }^{49}$ where Maori patients are meeting barriers to geographically, financially and culturally accessible best practice care along the clinical pathway, ${ }^{50}$ including access to specialist surgeons and surgical teams. ${ }^{51}$ These observations are in keeping with other international evidence of inequities in postoperative mortality for minority racial/ethnic groups ${ }^{52-54}$ : for example, a recent meta-analysis focussing on racial differences in coronary artery bypass graft procedures found that compared with white patients, black patients had a $25 \%$ increased risk of death in hospital when adjusted for both patient-level and hospital-level factors (OR 1.25, $95 \%$ CI 1.13 to 1.39$).^{55}$

The strong relationship observed between risk of death and patient comorbidity (and ASA level) is consistent with other large cohort studies. ${ }^{39}$ The most straightforward explanation is that those with comorbidity are more likely to have complications and/or die shortly after surgery because they are simply sicker than those without comorbidity; however, this relationship is also likely to be influenced by procedure type within specialties (although the latter should have been largely accounted for when adjusting for procedure risk within our Cox models). While increasing levels of comorbidity likely necessitate increasing surgical intervention, it is also worth noting that high-risk procedures might not be offered to some patients with severe comorbidity for the perceived risk of causing more harm than benefit. ${ }^{56}$

A key strength of this study is the national and temporal coverage of the surgical cohort and outcome data. New Zealand has universal healthcare, and as such most procedures are publicly funded ${ }^{57} 58$; however, we also augmented our analysis to include those private hospitals that report data to the national collections. In addition, the data linkage available in New Zealand means that we were able to follow patients beyond their discharge from hospital, in order to measure 30-day and 90-day mortality outcomes. There are few other international contexts able to conduct such national studies with the existing routine data. ${ }^{16}$

We decided to focus exclusively on procedures performed under general anaesthesia rather than including neuraxial block and/or regional anaesthesia. The primary purpose for this was to account for the insult of the general anaesthesia itself as part of the risk of postoperative mortality. We acknowledge that some key procedures are performed under both general anaesthetic and neuraxial/regional block, and that selection of anaesthetic will be patterned by some of the key variables investigated in this study (including age and comorbidity). A comparison of postoperative mortality outcomes between procedures commonly performed under either general anaesthesia or neuraxial/regional block is currently underway. Due to data limitations, it was not possible in our study to adequately investigate the role of hospital volume or clustering of patients at a hospital level.

\section{CONCLUSION}

The rate of postoperative death following an acute or elective/waiting list procedure in New Zealand is similar to that observed in other developed countries. However, as in other contexts, we observed that the likelihood of postoperative death was not proportionally distributed within our population: older patients, Māori patients, those living in areas with higher deprivation and those with comorbidity are at increased risk of postoperative death, even after adjusting for all available factors that might explain differences within these groups. Increasing surgical risk of the procedure being performed was also associated with an increased risk of postoperative death. Encouragingly, it appears that the risk of postoperative mortality has declined over the past decade, possibly reflecting improvements in perioperative quality of care; however, this decline did not occur equally across all procedure specialties.

\section{Author affiliations}

${ }^{1}$ Department of Public Health, University of Otago Wellington, Wellington, New Zealand

${ }^{2}$ Department of Anaesthesia and Perioperative Medicine, Auckland DHB Anaesthesia, Auckland District Health Board, Auckland, New Zealand

${ }^{3}$ Department of Statistics, The University of Auckland, Auckland, New Zealand ${ }^{4}$ Department of Surgery and Anaesthesia, University of Otago, Wellington, New Zealand

${ }^{5}$ Department of General Surgery, Capital and Coast District Health Board, Wellington, New Zealand

${ }^{6}$ Department of Anaesthesia, Capital and Coast District Health Board, Wellington, New Zealand

${ }^{7}$ Department of General Surgery, Waitemata District Health Board, Takapuna, New Zealand

${ }^{8}$ Department of Anaesthesia, Canterbury District Health Board, Christchurch, New Zealand

Acknowledgements We would like to acknowledge Chris Lewis at the Ministry of Health's National Collections team for his excellent assistance with data extraction.

Contributors JKG led manuscript concept and design, led the analysis of data, drafted the manuscript and revised content based on feedback. JS provided biostatistical support, assisted with interpretation of data and provided critical revision of drafts. MM, DC, ED, SJ, JK, LB and DO assisted with interpretation of data and provided critical revision of drafts. DS assisted with study concept and design, assisted with interpretation of data and provided critical revision of drafts

Funding This study was funded by the Health Research Council of New Zealand (HRC reference \# 18/037).

Competing interests None declared.

Patient and public involvement Patients and/or the public were not involved in the design, or conduct, or reporting, or dissemination plans of this research.

Patient consent for publication Not required. 
Ethics approval The study received ethical approval from the University of Otago Human Ethics Committee (reference: H18/085).

Provenance and peer review Not commissioned; externally peer reviewed.

Data availability statement Data may be obtained from a third party and are not publicly available. The data used for this study were provided following ethical review from the New Zealand Ministry of Health National Collections team. Data requests can be made by contacting data-enquiries@health.govt.nz.

Open access This is an open access article distributed in accordance with the Creative Commons Attribution Non Commercial (CC BY-NC 4.0) license, which permits others to distribute, remix, adapt, build upon this work non-commercially, and license their derivative works on different terms, provided the original work is properly cited, appropriate credit is given, any changes made indicated, and the use is non-commercial. See: http://creativecommons.org/licenses/by-nc/4.0/.

\section{ORCID iDs}

Jason K Gurney http://orcid.org/0000-0002-7615-0748

Melissa McLeod http://orcid.org/0000-0002-5834-7846

James Stanley http://orcid.org/0000-0002-8572-1047

\section{REFERENCES}

1 Nepogodiev D, Martin J, Biccard B, et al. Global burden of postoperative death. Lancet 2019;393:401.

2 Perioperative Mortality Review Committee. Perioperative mortality in New Zealand: sixth report of the perioperative mortality review Committee. Wellington: Health Quality \& Safety Commission, 2017.

3 Campbell D, Boyle L, Soakell-Ho M, et al. National risk prediction model for perioperative mortality in non-cardiac surgery. Br J Surg 2019;106:1549-57.

4 Endo I, Kumamoto T, Matsuyama R. Postoperative complications and mortality: are they unavoidable? Ann Gastroenterol Surg 2017;1:160-3.

5 Gurney JK, Stanley J, Rumball-Smith J, et al. Postoperative death after lower-limb amputation in a national prevalent cohort of patients with diabetes. Diabetes Care 2018;41:1204-11.

6 Massarweh NN, Legner VJ, Symons RG, et al. Impact of advancing age on abdominal surgical outcomes. Arch Surg 2009;144:1108-14.

7 McNicol L, Story DA, Leslie K, et al. Postoperative complications and mortality in older patients having non-cardiac surgery at three Melbourne teaching hospitals. Med J Aust 2007;186:447-52.

8 DiBardino DJ, Pasquali SK, Hirsch JC, et al. Effect of sex and race on outcome in patients undergoing congenital heart surgery: an analysis of the Society of thoracic surgeons congenital heart surgery database. Ann Thorac Surg 2012;94:2054-60.

9 Oster ME, Strickland MJ, Mahle WT. Racial and ethnic disparities in post-operative mortality following congenital heart surgery. $J$ Pediatr 2011:159:222-6.

10 DiBardino DJ, Pasquali SK, Hirsch JC, et al. Effect of sex and race on outcome in patients undergoing congenital heart surgery: an analysis of the society of thoracic surgeons congenital heart surgery database. Ann Thorac Surg 2012;94:2054-60.

11 Sukumar S, Ravi P, Sood A, et al. Racial disparities in operative outcomes after major cancer surgery in the United States. World $J$ Surg 2015;39:634-43.

12 Chan T, Lion KC, Mangione-Smith R. Racial disparities in failureto-rescue among children undergoing congenital heart surgery. $J$ Pediatr 2015;166:812-8.

13 Dean PN, McHugh KE, Conaway MR, et al. Effects of race, ethnicity, and gender on surgical mortality in hypoplastic left heart syndrome. Pediatr Cardiol 2013;34:1829-36.

14 Lemaire A, Cook C, Tackett S, et al. The impact of race and insurance type on the outcome of endovascular abdominal aortic aneurysm (AAA) repair. J Vasc Surg 2008;47:1172-80.

15 Lasa JJ, Cohen MS, Wernovsky G, et al. Is race associated with morbidity and mortality after hospital discharge among neonates undergoing heart surgery? Pediatr Cardiol 2013;34:415-23.

16 Perioperative Mortality Review Committee. Perioperative mortality in New Zealand: fifth report of the perioperative mortality review Committee. Wellington: Health Quality \& Safety Commission, 2016.

17 Leigh Y, Seagroatt V, Goldacre M, et al. Impact of socio-economic deprivation on death rates after surgery for upper gastrointestinal tract cancer. Br J Cancer 2006;95:940-3.

18 Poulton TE, Salih T, Martin P, et al. Systematic review of the influence of socioeconomic deprivation on mortality after colorectal surgery. $\mathrm{Br}$ J Surg 2018;105:959-70.
19 Barnard J, Grant SW, Hickey GL, et al. Is social deprivation an independent predictor of outcomes following cardiac surgery? an analysis of 240,221 patients from a national registry. BMJ Open 2015;5:e008287.

20 Roche JJW, Wenn RT, Sahota O, et al. Effect of comorbidities and postoperative complications on mortality after hip fracture in elderly people: prospective observational cohort study. BMJ 2005;331:1374.

21 Chou W-C, Chang P-H, Lu C-H, et al. Effect of comorbidity on postoperative survival outcomes in patients with solid cancers: a 6-year multicenter study in Taiwan. J Cancer 2016;7:854-61.

22 Clough RA, Leavitt BJ, Morton JR, et al. The effect of comorbid illness on mortality outcomes in cardiac surgery. Arch Surg 2002;137:428-33.

23 Ministry of Health. National minimum dataset data Mart dictionary. Wellington: Ministry of Health, 2018.

24 Ministry of Health. Certified health care providers Wellington, New Zealand, 2020. Available: https://www.health.govt.nz/your-health/ services-and-support/certified-providers

25 Ministry of Health. Privately funded hospital discharges - series Wellington, New Zealand, 2019. Available: https://www.health.govt. $\mathrm{nz} / \mathrm{nz}$-health-statistics/health-statistics-and-data-sets/privatelyfunded-hospital-discharges-series

26 Ministry of Health. National health index data dictionary. Wellington: Ministry of Health, 2009.

27 National Centre for Classification in Health. The international statistical classification of diseases and related health problems, tenth revision, Australian modification (ICD-10-AM/ACHI/ACS). 3 edn. Darlinghurst, NSW, Australia: Independent Hospital Pricing Authority, 2002.

28 Pasternak RL. Preanesthesia evaluation of the surgical patient. Anesthesiology 1996;24:205-19.

29 Health Information Standards Organisation. HISO 10001:2017 ethnicity data protocols. Wellington, New Zealand: Ministry of Health, 2017.

30 Salmond CE, Crampton P. Development of New Zealand's deprivation index (NZDep) and its uptake as a national policy tool. Can J Public Health 2012;103:S7-11.

31 Robson B, Purdie G, Cormack D. Unequal impact II: Māori and Non-Māori cancer statistics by deprivation and rural-urban status, 2002-2006. Wellington: Ministry of Health, 2010.

32 Stanley J, Sarfati D. Development and validation of the M3 index for measuring multimorbidity load for risk of mortality. J Clin Epidemiol 2017:95:99-110.

33 Harrell FE. Regression modeling strategies: with applications to linear models, logistic regression, and survival analysis. 2 edn. Cham: Springer, 2015.

34 Sawada S, Suehisa H, Ueno T, et al. Changes in post-operative complication and mortality rates after lung cancer resection in the 20-year period 1995-2014. Acta Med Okayama 2016;70:183-8.

35 Statistics New Zealand. Estimated residential population dataset Wellington, New Zealand, 2019. Available: http://archive.stats.govt. nz/infoshare [Accessed 20 Nov 2019].

36 Gurney JK, Stanley J, Rumball-Smith J, et al. Postoperative death after lower-limb amputation in a national prevalent cohort of patients with diabetes. Diabetes Care. In Press 2018;41:1204-11.

37 Ramsay G, Haynes AB, Lipsitz SR, et al. Reducing surgical mortality in Scotland by use of the WHO surgical safety checklist. Br J Surg 2019;106:1005-11.

38 Yu P, Chang DC, Osen HB, et al. NSQIP reveals significant incidence of death following discharge. J Surg Res 2011;170:e217-24.

39 Pearse RM, Moreno RP, Bauer $\mathrm{P}$, et al. Mortality after surgery in Europe: a 7 day cohort study. Lancet 2012;380:1059-65.

40 Strand T-E, Rostad H, Damhuis RAM, et al. Risk factors for 30-day mortality after resection of lung cancer and prediction of their magnitude. Thorax 2007;62:991-7.

41 Nepogodiev D, Omar O, Bhangu A. Reducing postoperative mortality rates in England. Br J Surg 2019;106:1099-100.

42 Berstock JR, Beswick AD, López-López JA, et al. Mortality after total knee arthroplasty: a systematic review of incidence, temporal trends, and risk factors. J Bone Joint Surg Am 2018;100:1064-70.

43 Gadiparthi C, Ali Khan M, Imam M, et al. Temporal trends and predictors for post-operative inpatient mortality in gastric cancer. Am $J$ Gastroenterol 2017;112:S671.

44 Ivanov J, Weisel RD, David TE, et al. Fifteen-year trends in risk severity and operative mortality in elderly patients undergoing coronary artery bypass graft surgery. Circulation 1998;97:673-80.

45 Ministry of Health. Enhanced recovery after surgery Wellington, New Zealand, 2015. Available: https://www.health.govt.nz/our-work/ hospitals-and-specialist-care/enhanced-recovery-after-surgery [Accessed 1 Dec 2019]. 
46 Ferrah N, Stephan K, Lovell J, et al. Rural centres do not have a higher prevalence of post-operative complications than urban centres: a retrospective analysis of a mortality audit. ANZ J Surg 2019;89:833-41.

47 Wang TKM, Ramanathan T, Stewart R, et al. Maori have worse outcomes after coronary artery bypass grafting than Europeans in New Zealand. N Z Med J 2013;126:12-22.

48 Hill S, Sarfati D, Blakely T, et al. Survival disparities in Indigenous and non-Indigenous new Zealanders with colon cancer: the role of patient comorbidity, treatment and health service factors. J Epidemiol Community Health 2010;64:117-23.

49 Tribunal W. HAUORA: report on stage one of the health services and outcomes kaupapa inquiry - WAI 2575. New Zealand: Lower Hutt, 2019.

50 Koea J, Ronald M. What do Indigenous communities want from their surgeons and surgical services: a systematic review. Surgery 2020;167:661-7.

51 Roberts E, Delgado Nunes V, Buckner S, et al. Paracetamol: not as safe as we thought? A systematic literature review of observational studies. Ann Rheum Dis 2016;75:552-9.

52 Kennedy BS. Does race predict short-term mortality after carotid surgery? the results of a meta-analysis. J Natl Med Assoc 2002;94:25-30.
53 Schoenfeld AJ, Tipirneni R, Nelson JH, et al. The influence of race and ethnicity on complications and mortality after orthopedic surgery: a systematic review of the literature. Med Care 2014;52:842-51.

54 Peterson K, Anderson J, Boundy E, et al. Mortality disparities in racial/ethnic minority groups in the Veterans health administration: an evidence review and MAP. Am J Public Health 2018;108:e1-11.

55 Benedetto U, Kamel MK, Khan FM, et al. Are racial differences in hospital mortality after coronary artery bypass graft surgery real? A risk-adjusted meta-analysis. J Thorac Cardiovasc Surg 2019;157:2216-25.

56 Hill S, Sarfati D, Robson B, et al. Indigenous inequalities in cancer: what role for health care? ANZ J Surg 2013;83:36-41.

57 Ministry of Health. Publicly funded hospital discharges - 1 July 2016 to 30 June 2017 Wellington, New Zealand, 2019. Available: https:// www.health.govt.nz/publication/publicly-funded-hospital-discharges1-july-2016-30-june-2017 [Accessed 9 Dec 2019].

58 Ministry of Health. Privately funded hospital discharges - 1 July 2016 to 30 June 2017 Wellington, New Zealand, 2019. Available: https://www.health.govt.nz/publication/privately-funded-hospitaldischarges-1-july-2016-30-june-2017 [Accessed 9 Dec 2019]. 